\section{Partner crop plants with solar facilities}

About one million hectares of land will be required in the United States by 2030 to meet solar-energy targets (go.nature. com $/ 2$ g5hkg). Cultivating carefully selected plants on such sites could offer a sustainable solution to meeting growing food and energy demands, particularly in regions with limited agricultural land and water resources (see, for example, go.nature.com/acixb7 and go.nature.com/n2sysg).

Photovoltaics (for producing electricity) and photosynthesis (for producing food, fodder or biofuel) both need sunlight. Large solar infrastructures protect vegetation from intense sun and strong winds, and regular washing of their surfaces provides water for the plants. Crops could be grown in the spaces between these structures to benefit from concentrated rainfall. These crops would reduce dust from disturbed soils, which could otherwise lower the efficiency of solar installations, and they would create extra revenue and employment.

The benefits and trade-offs of such co-located systems are now being evaluated (see, for example, go.nature.com/ acixb7 and S. Ravi et al. Environ. Sci. Technol. 48, 3021-3030; 2014). And solar operators and investors in North Africa, India, Mexico and the United States are already expressing an interest (S. R., personal communication). Sujith Ravi Temple University, Philadelphia, Pennsylvania, USA. sravi@temple.edu

\section{STEM teaching: use more innovations}

Two other concerns should be added to your prescriptions for improving teaching in science, technology, engineering and mathematics (STEM; see Nature 523, 272-274 and 282-284; 2015).

We know that smaller class sizes and classrooms designed for active learning give better academic outcomes (S. Cotner et al. J. Coll. Sci. Teach. 42, 82-88; 2013), yet budgetary pressures discourage institutions from abandoning big lecture halls in favour of small classes.

Also, there should not be separate faculty tracks for teaching and research. Teaching positions rarely include research support, so they do not offer the same academic opportunities as research faculty positions.

These issues are ultimately about institutional and administrative buy-in. The success of STEM students depends on institutions investing in improved learning facilities and on administrators providing research, tenure and promotion opportunities for those who teach. Luke Holbrook Rowan University, Glassboro, New Jersey, USA. holbrook@rowan.edu

\section{STEM teaching: avoid Swiss-cheese effect}

You propose a shift from traditional university lectures to a system that teaches the methods of scientific enquiry to students of science, technology, engineering and mathematics (STEM; see Nature 523, 272-274 and 282-284; 2015). This move has clear merits, but systematic transfer of the requisite knowledge should not be abandoned entirely.

A pioneer in active-learning practices, Roskilde University in Denmark has been using problem-based teaching and successfully involving students in research since 1972. Our experience shows, however, that there are potential pitfalls.

Unless critical thinking is allied with a strong fundamental knowledge base, there is a risk that students will develop a 'Swiss cheese' understanding of science - with a good grasp of their chosen subject areas but major gaps in others. This can produce niche researchers who lack a proper understanding of their wider field.
We therefore advise retaining aspects of traditional education in an appropriate balance, which is then adjusted on the basis of student and course evaluations. Farhan R. Khan, Gary T. Banta Roskilde University, Denmark. Christina Sørensen University of Oslo, Norway.

frkhan@ruc.dk

\section{The future of public trust in science}

The challenges of maintaining trust in science (see Nature 522, 6 ; 2015) can be understood in terms of corrupting pressures that make it harder for scientists to do the good work to which many aspire.

The sheer scale of science today is destroying colleague communities; it also demands 'objective' metrics of quality, which are perverse and corruptible. These effects are compounded by imported commercial pressures. The idealism that motivated 'little science' is no longer plausible.

Maintaining the public's trust in science calls for an urgent evaluation of its imperfections and vulnerabilities. We must identify what needs to be unlearned in the prevalent understanding of science: for example, we now know that any science-related policy problem poses more questions and solutions than can be derived from the illusory precision of models and indicators (a factor in the 2008 financial crisis).

Social-media channels are starting to teach the public more about new views of science. The growth of 'DIY science', which owes only minimal deference to established institutions, will eventually influence science education, and to good effect. In much the same spirit as citizen science has developed in parallel with established science, a movement of scientifically aware citizens could emerge within science. These citizens would develop an understanding of the connection between science's internal problems, such as morale and quality assurance, and external pressures of the sort we describe. Jerome Ravetz University of Oxford, UK.

Andrea Saltelli University of

Bergen, Norway.

jerome.ravetz@gmail.com

\section{Solar ovens beaten by rain and tortillas}

Solar ovens sometimes fall short of their promise as the gold standard of clean cooking, despite producing zero emissions (see L. S. Brown and W. F. Lankford Nature 521, 284-285; 2015).

In a solar-oven project funded by the Central American Solar Energy Project (CASEP) in Nicaragua, participants generally reported large fuel savings. Yet objective measurements found that savings were not significant, and surveys indicated that users continued to cook on biomass-burning stoves. Data from thermometers inside solar ovens confirmed that oven usage was widely over-reported (see go.nature.com/oqff6a).

Furthermore, although the 77 Nicaraguan women interviewed in 2014 (by S.V.) found CASEP's empowerment training helpful, this did not result in self-sustaining community action after the project ended.

In parts of Latin America, preparing tortillas accounts for more than half of cooking fuel usage (O. Masera et al. Energy Sustain. Dev. 11, 45-56; 2007), but tortilla preparation is impossible with most solarcooker designs because they are not hot enough. And in areas with a rainy season, solar cooking is impractical for half of the year. Improved biomass stoves and biogas might be more effective solutions in such regions.

Gordon Bauer University of Oslo, Norway.

Sarah Vukelich Williams

College, Williamstown,

Massachusetts, USA.

gordon.bauer@gmail.com 